\title{
KNOWLEDGE VISUALIZATION TECHNIQUE ON THAI DANCE MOVEMENT THROUGHT GAME-BASED LEARNING
}

\section{YOOTTHAPONG TONGPAENG ${ }^{1}$, SUEPPHONG CHERNBUMROONG ${ }^{2}$ PRADORN SUREEPHONG $^{3}$, KARIM TABIA ${ }^{4}$}

${ }^{1,2,3}$ College of Arts, Media and Technology, Chiang Mai University, Thailand

${ }^{4}$ CRIL UMR CNRS, Universite d'Artois, Arras, France

\begin{abstract}
Traditional Thai dance is one of the valuable intangible cultural heritage in the Southeast Asia region. Yet, the government reported the dramatically reduced number of Thai dance teachers and Thai dance students registering to the College of Dramatic Arts, Thailand. The statistic of students who enrolled at the college of dramatic arts, Thailand, from the last four years was surprisingly reduced and effected to a valuable cultural knowledge that must be maintained, preserved, and transferred as a living traditional art form in the future. Previously, the AniAge project had been proposed the Thai dance training tool with the aim of transferring the Thai dance knowledge and improve the Thai dance student performance. The tool provides the Thai dance students a process of practicing with a game-based learning method and the evaluating method. In the paper, twenty students from Chiang Mai College of Dramatic Arts, Thailand, participated using the Thai dance training tool. The evaluation was separated into two evaluations, which are performance evaluation and satisfaction evaluation. Overall, the performance evaluation indicated that the control group participants perform better than the experimental group. Nevertheless, the Thai dance training tool provided a good learning environment for the Thai dance students, which enhanced their performance. We believe that the Thai dance training tool will become the innovation platform for improving Thai dance students' performance.

KEYWORDS: Traditional Thai dance, Intangible Cultural Heritage, AniAge project, Thai dance training tool, Transfer Knowledge, Performance Evaluation, Satisfaction Evaluation
\end{abstract}

Received: Dec 24, 2020; Accepted: Jan 14, 2021; Published: Jan 22, 2021; Paper Id.: IJMPERDFEB202110

\section{INTRODUCTION}

In the present-day, cultural heritage is an expression of living developed by society and passed on from generation to generation, including customs, practices, places, objects, artistic expressions, and values. Cultural Heritage is often expressed as either Intangible or Tangible Cultural Heritage [10]. UNESCO has listed the living traditional art form as the Intangible Cultural Heritage (ICH) worldwide. Southeast Asia is one of the fastest-growing regions with natural and cultural resources worldwide. Intangible cultural heritage is precious cultural information that must be protected and preserved as a living traditional art form, such as traditional dances or folk dance. [20]. Traditional Thai dance is one of the traditional living forms of art in which UNESCO listed its origin, community, emotional expression, and body movement for such a special and stylized traditional dance. An expression of the living culture must remain an integral component of a functioning society, such as traditions, activities, locations, artifacts, creative expressions, and values passed on to the next generation [21]. A living traditional art form that must be preserved as knowledge. Hence. Thai dance knowledge is related to two characteristics of knowledge: tacit knowledge and explicit knowledge. The 
tacit knowledge is difficult to transfer through writing and telling, same as Thai dance knowledge, which is difficult to teach and learn. The reduced enrollment rate for the college of a dramatic arts school in the last four years.

Therefore, the technology of visualization nowadays had been developed to help the researcher record, display, and analyze the data using a motion capture system, Microsoft Kinect motion sensor, to transform human movement into motion data such as 3D digital animation. For example, Motion Capture is the process used in sport, medicine, robotics, and entertainment to record humans or objects' movement. It refers to recording human actors in video game production and using motion data to animate digital character models in 3D computer animation, including facial expressions, finger gestures, etc. [9]. Nevertheless, these technologies still need improvement in learning motivation to engage the learner to complete their learning objective.

In 2017, In order to preserve the performing art-related ICHs of Southeast Asia, the AniAge project aimed to develop novel techniques and tools to reduce production costs and improve the level of automation without sacrificing artists' control. [1]. Besides, the tool called "Thai dance training tool" was implemented for transfer Thai dance knowledge with game-based learning method in this project. The purpose of this paper is to evaluate student performance in Thai dance. Of the Thai dance students, twenty were participants. Since they were 12 years old, all of them have had the experience of learning Thai dance. The experience that they do not have was using computer games as a learning process. It will give us an unexpected result in the evaluation process and discussion.

\section{LITERATURE REVIEW}

\subsection{Background and Problem Statement}

The performing arts associated with music are traditional Thai dance, performing with unique dance styles in different regions, with different names. The climate, terrain, faith, religion, language, people's attitude, and life are mainly due to [16]. Therefore, like many kinds of traditional Asian dance, Thai dance is mainly a dramatic art form. Traditional Thai dance can be divided into two main groups that refer to the distinction between High Art (classical dance) and Low Art (folk dance) [11]. Khon dance is the high art or Thai classical dance-drama using Thai dance techniques that involve many postures influenced by Indian dance techniques, adapted from the Natyashastrastra's initial set of 108 karanas (Shiva Nataraja) [11]. King Rama 2 involved in Thai literature after the Ayutthaya war and recovered the dance style from becoming more delicate and elegant. By drawing on the Thai dance movement's fundamentals for 66 postures, the first Thai dance textbook was developed. [18]. From time to time, the textbook had been improved from the black and white vision to color version, the photo with deceptions of the movement, the black and white filming to color filming, and video recording to motion capturing three-dimension animation.

However, Thai dance teaching and learning moves from generation to generation with one-on-one teaching and practice focused on Thai dance terminology from teacher to student. Students had to memorize the meaning of a gesture, movement, and practice repeatedly. Students studied Thai dance based on the step-by-step dance movement practice at three levels: terminology terms, body language terms, and performance terms. The term terminology is the fundamental posture that states the actions of the person. Such as Jeeb, Wong, etc., In order to convey one emotional gesture or one action, the term body language blends different simple postures. Such as Phra Ram is sitting down and angry. The performance term is the combination of body language to convey the character's emotion in the scene. Each level of knowledge offers a movement and dance complexity to convey the emotion of the character. At present, there are 12 colleges of dramatic arts established 
all around Thailand, which provided a Thai dance curriculum with 1,201 teachers and 15,357 students under the ministry of culture, Thailand [15]. However, the number of Thai dance instructors, as well as Thai dance students, is drastically reduced year after year. Due to the complexity of the learning process, based on the Thai dance teacher's tacit knowledge. Tacit knowledge, as Nonaka said, "It is hard to formalize... difficult to communicate...deeply rooted in action and in an individual's commitment to a specific context...captured in the term 'know-how'. It consists of mental models, beliefs, and perspectives so ingrained that we take them for granted, and therefore cannot easily articulate them". [12] It is not easy to transfer to another individual or group of people through writing or speaking. Generally, there are two characteristics of knowledge, which is tacit knowledge and explicit knowledge. Tacit knowledge is the type of knowledge in which difficult to transfer to another person. According to Nonaka and Takeuchi's book The Knowledge-Creating Company in 1995, tacit knowledge is the knowledge that, through experience and jobs, is embedded in the human mind. It is more difficult to extract and codify. Tacit knowledge is included in insights and intuitions [12]. Explicit knowledge is a type of knowledge that can be readily articulated, codified, stored, and accessed. Additionally, it can be transferred to another, which can be stored in certain media [8]. The books, documents, reports, memos, etc., explicit knowledge can be codified and digitized. The knowledge is simply identified, articulated, shared, and employed [12]. Thai dance knowledge, which is embedded in the Thai dance expert's mind, is considered tacit knowledge. The knowledge that difficult to transfer by means of writing it down or verbalizing it. Consequently, the AniAge project had begun to transform tacit knowledge from Thai dance knowledge into explicit knowledge as 3-dimensional tracking data [23].

\subsection{Knowledge Archive and Transfer}

Normally, to transform tacit knowledge into explicit knowledge in dancing began in the $14^{\text {th }}$ century [2]. This main consideration of archive dance knowledge was to record and teach the knowledge to the next generation. This is very important that the knowledge would not vanish. The knowledge provided evidence of dancing activities and told us more about individuals, groups, and increasing our sense of identity and understanding of cultures. Since the $14^{\text {th }}$ century, dance knowledge had been archived as a dance notation system by the different notators and different methods. Word or Word Abbreviations, Track Drawings, Stick Figure (Visual) Systems, Music Note Systems, and Abstract Symbol Systems are five categories of dance notation systems [2]. The first evidence discovered in 1450 DC was the Burgundian manuscript known as "The Dance Book of Margaret Of Austria." It was later passed on to Margaret's daughter, Mary of Hungary, and is now in the Brussels Royal Library. The book explains the dance movement in silver and gold on black paper in which each letter was placed under the proper music note using the Word Abbreviation method [2]. In the $18^{\text {th }}$ century, the first stick figure system had implemented for the ballet dance called the "Saint-Léon System." Arthur Saint-Léon published it in Paris, France. The notation system was developed by Léon and used in the book "the Pas de Six from La Vivandière" [2]. By reading gesture signs of the stick figure symbols along with the music notes, Léon used stylized legs and arms as the indications that give only one dancer notation. Another important dance notation system is an abstract symbol system invented in 1928 and widely used for the ballet dance was the Labanotation system. The system was invented by Rudolf von Laban, the AustroHungarian dance artist. As the' Founding Father of Expressionist Dance' in Germany, Rudolf is regarded as one of the pioneers of modern dance in Europe. Rudolf von Laban's first approach is to write notation in vertical reading in the same way as reading a text. Nevertheless, for practical purposes, the notation was written horizontally; one just turns the page [2]. The Labanotation system had been improved version by version and not only for the ballet dance. The ability of this system is to be able to record all the human movement. 
A professor, Thai dance master, and scholar, Prof. Dr. Chommanad Kijkhun, experimented on archiving Thai dance movement using the Labanotation method. Hence, the system provided an overload of symbols to record such complex, delicacy moves of Thai dance. Therefore, the professor designed new symbols to describe Thai dance and a reduced amount of time for the Labanotation score to be written down. Most new design symbols represent the basic hand gesture, such as Jeeb and Wong, for the Thai dance notation system [5]. However, learning how to write a Labanotation score is not easy. Students will have to understand the basics of writing Laban symbols and learn how to write the Thai dance notation symbols, which are very complex and take years to become a professional notator.

Therefore, using technology to archive Thai dance moves had begun in the AniAge project by using Motion Capture System to record Thai dance moves as the motion data at College of Arts, Media and Technology, Chiang Mai University [23]. The EvaRT software of Motion Analysis Company used the record the Thai dance motion and was used to clean data after the record. Thai dance expert who wears a Motion Capture suit with 42 markers were involved in this process: five head markers, eight shoulder-to-arm markers on both sides, six markers on both hands, two markers on the front body, and three markers on the back of the body, four markers on the waist, four markers on both legs and ten markers on both feet. This motion data was prepared to be used in Thai dance training tool or Thai dance game-based learning that included motion capture data from the Microsoft Kinect Motion Sensor and real-time motion data [13] [22]. The training tool provided the students with learning how to moves gesture by gesture. Students will see the demonstration from the tool before start the movement. The demonstration will remind the student about the gesture. In addition, the tool provided the students feedback by mean of scores. Two scores were provided from the tool: body part scores and total score. Body parts score is the feedback from each part of the body such as right arm, left arm, right leg, head, etc... And the total scores are the overall score [13] [17]. Using the Thai dance game-based learning method, the Thai dance training tool is the tool for transferring Thai dance knowledge to Thai dance students to encourage students to practice their Thai dance class movement.

\subsection{Game-Based Learning}

Game-based learning is the educational approach that involves the game concept in a learning process. Also, Game-based learning is an efficient approach that provides learners with learning motivation and learning outcomes [19]. Game-based learning Integrated with a digital game, instructional content would enable the learner to achieve learning goals. Cheung et al. discovered the learning material that could apply the digital game to the learning outcome and benefits in order to achieve learning goals. [3]. Game-based learning is a successful method due to the integration of learners with game characteristics. For instance: play, rules, objectives, interactive, performance, feedback, adaptive, winning states, conflict, competition, challenge, opposition, problem-solving, interaction, representation, story, and fun [14]. Designing a learning game for the learner required the game styles and elements from the game characteristic list with instructional content. Thus, the combination of Thai dance gesture knowledge and game-based learning would provide the learner's interest, challenge the learner, enhance motivation, active learning, and improve learning outcomes. In the field of learning games, the inputprocess-outcome (IPO) game-based learning model is recognized [6]. IPO game-based learning typically aims to develop an instructional game that increases the learning performance of the learner. A motivation-oriented data, method, and result game model is also intended for the education game [7]. The development of a Kinect-based somatosensory IPO and ARCS model interface allows the learner to use their physical movements to manipulate virtual characters [4].

Consequently, the instructional content of the Thai dance and IPO game-based learning model is mixed to create the proposed game-based Thai dance training model. Based on the Input-Process-Outcome (IPO) game-based learning 
model, the model is divided into three states., as shown in fig 1. [17].

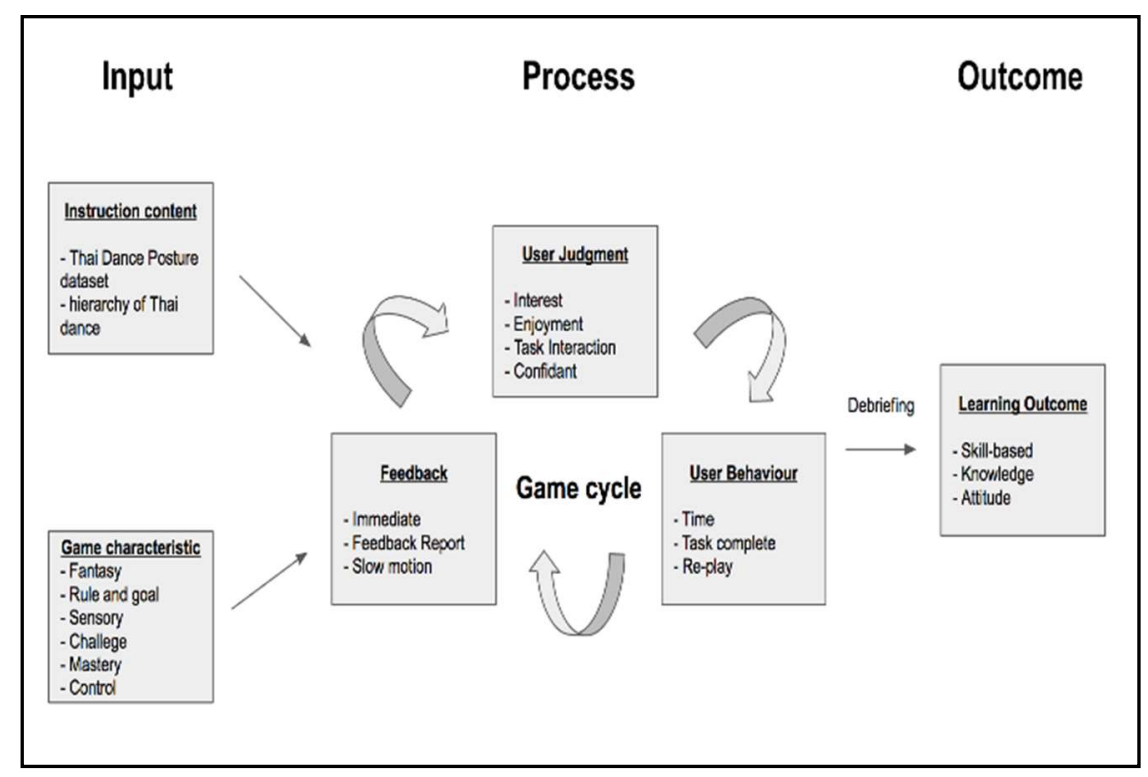

Figure 1: Thai dance training game-based model

Input State: Instructional Content - The learning goals of our research was to train Thai dance gestures and movements, verified by the expert, with the training system for a student at Chiang Mai College of Dramatic Arts in Thailand. Game Characteristics - Six dimensions will characterize it: fantasy, rules/goals, sensory stimuli, challenge, mystery, and control. Fantasy: It helps users to interact in situations that are not part of the everyday experience. As a fantasy story for the learner to explore, the history of Thai dance was introduced. Besides, the student will be able to control the avatars. Rules/Goals: The goal structure of the game was described as the rules of the game. To perform a Thai dance, the user first requires a 3D animation demonstration of the action. Then the gesture can be repeated by the user. Depending on the results, a score is given, and the next step is unlocked. Sensory Stimuli: the representation on the screen will be provided in the 3D animation environment. By engaging with the instructional material, the system will allow the student to learn. Challenge: The system will include the challenge elements. For example, difficulty levels, multiple goals, and uncertain situation to ensure an uncertain outcome. The system also provided the leaderboard, which shows the rank of the overall learner's score. Hence, the learner will be able to see and compare their score to their friend. Mystery: The system is divided into three levels: basic level (dance terminology), intermediate level (body language), and advanced level (song). For instance, before unlocking the game and moving on to a higher level, the learner must complete all the tasks at a basic level. Control: By allowing the learner to choose the content and status of a level, the learner would be able to control the system directly. Besides, the learner can change the basic features. For example: replay the demonstration, fast forward the dance demonstration, etc. [17].

Process State: In a game context, the learner will repeat cycles as the device motivates the learner to play and practice the movement. Therefore, User judgment, user behaviour, and feedback are involved in the motivational process loop. User judgment: Four components are characteristically linked to user judgment. Fascinating, enjoyment, mission participation, and confidant. Then, using a quantitative method, we would observe and measure the learner's opinion. For example, the focus group in deep-interview, survey questionnaire, etc. User behaviour: The gameplay experiment is the primary factor in focusing on the learner's direction, intensity, and behaviour. System feedback: By expending more effort, 
persisting, and concentrating attention on the task, System feedback can push the motivation of the learner to a better result. The purpose is to show the learner the right motion and observe their own error [17].

Outcome State: It can be categorized into three kinds of differences: skill-based, cognitive, and affective effects. Therefore, in all types, the system would have a positive result. In skill-based, the learner should be better performed, acquire, and recognize the knowledge for a different type of Thai dance gesture. Additionally, in terms of affective responses or behaviours, the learner should have a positive result. For instance: feelings of confidence, self-efficacy, preferences, and attitudes [17].

\subsection{Game Design}

The flow of the Thai dance training tool, the menu stage, the gameplay process, and the result and feedback for users have been simplified by three key stages [22].

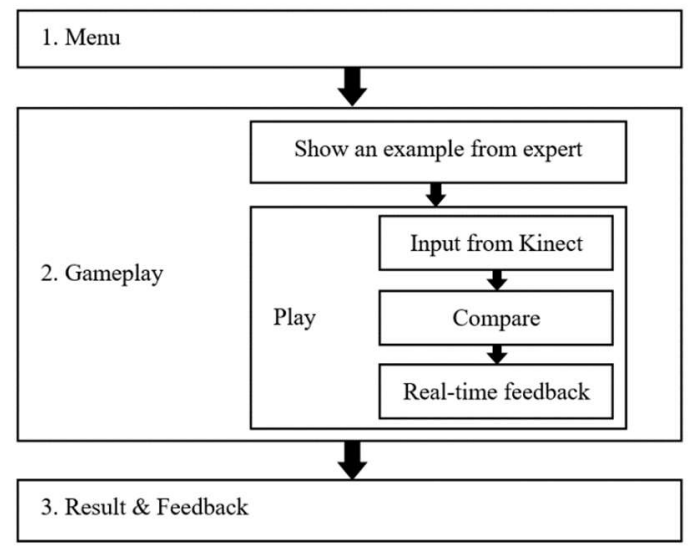

Figure 2: The application flow of the Thai dance training tool

Menu: The terminology choices are shown in the menu stage to encourage the user to select a dance move one by one. The user must post the Wong posture to start the training. And the system will make it possible for the user to go to the next level. There is an option for the user to choose a dance movement; each shows a high user score [22].

Gameplay: After the user had selected a dance movement. The system will start to display the demonstration video. After the video is completed, the user can start moving and practicing by seeing themselves as a 3D avatar. Meanwhile, input data from the Microsoft Kinect motion sensor will be captured by the device and compared with Motion Capture Data. At the end of the training, the device would show real-time feedback.

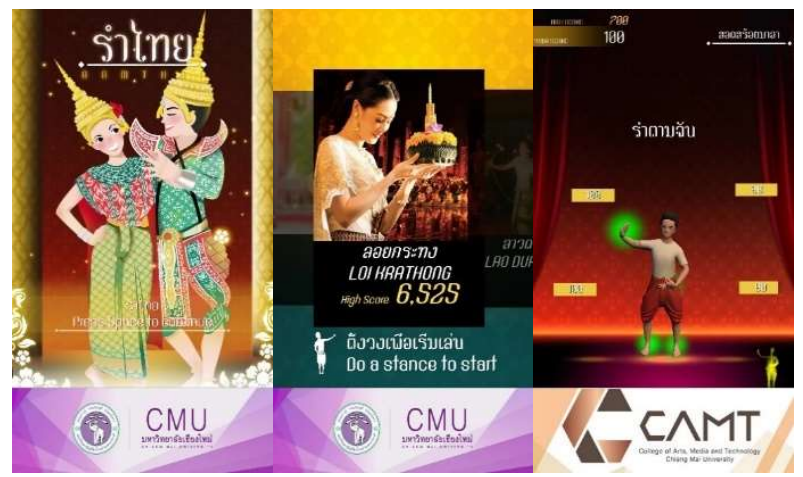

Figure 3: Example of menu and gameplay 
Result \& Feedback: A final result, assessed by the comparison process, will be shown by the system. The final result is displayed in the form of the score, and the leaderboard will be the last display to increase the motivation of the user [22].

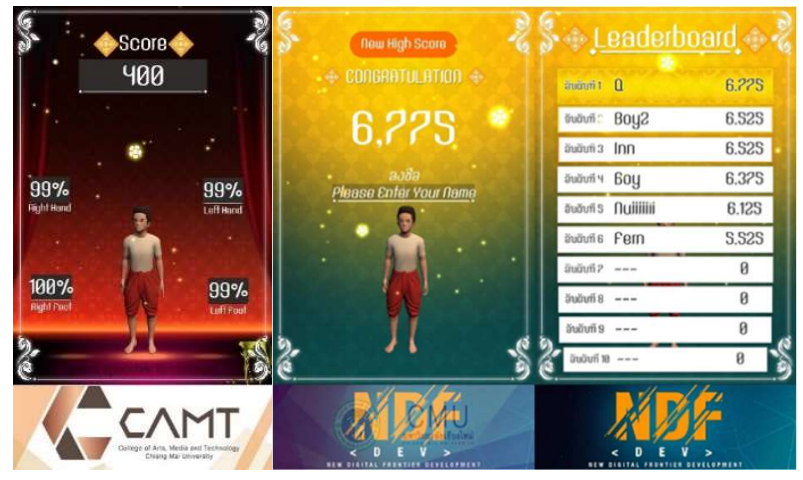

Figure 4: Example of Result and Feedback

\section{RESEARCH METHOD}

The main objective of these studies is to measure the performance of Thai dance students and their satisfaction. The experimental session included twenty students from Chiang Mai College of Dramatic Arts, Thailand. All personal information of participants is confidential.

\subsection{Participant}

According to the demographic information, most participants in all groups are 14-15 years old. A Male is eight, while a female is twelve. The educational background of most participants was secondary school. All of the participants have experience of Thai dance. This subject is their main curriculum in school. However, all of the participants never experienced using computer games in Thai dance class.

\subsection{Method}

There are 20 students participating at the Chiang Mai College of Dramatic Arts, Thailand. Based on different learning patterns, all students were divided into two groups (ten students in the control group and a further ten students in the experiment group). The control participants were assigned three classes a week to learn and practice with their teacher (2 hours per class). Beyond the class, they were allowed to practice by themselves with their friends and teachers. On the other hand, the experimental group participants were assigned to attend the class similar to the control group. However, they were offered a practice session with a computer game. The game is available limited time and is located in their classroom. 


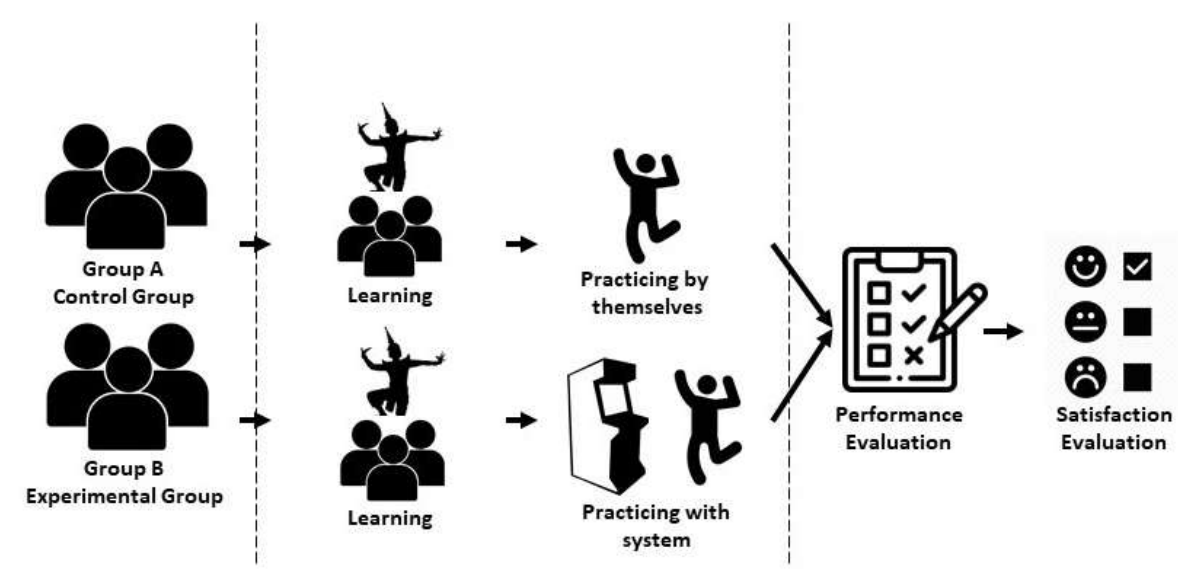

Figure 5: The evaluation method on the Thai dance training tool

In order to enroll and complete all learning activities in the class, the participants in all groups were assigned. Participants must have met the condition requirement by attending psychic class and practicing with their teacher or computer game in order to complete the learning activities. Participants were asked to evaluate for the task of performance evaluation. Within one week, participants had to complete the program. They were allowed, in their workplace or home, to learn and practice from their own interests. There was no penalty for all participants who were not able to complete the learning activities.

\subsection{Assessment}

For the assessment, there are two evaluations on this method; Performance Evaluation and Satisfaction Evaluation.

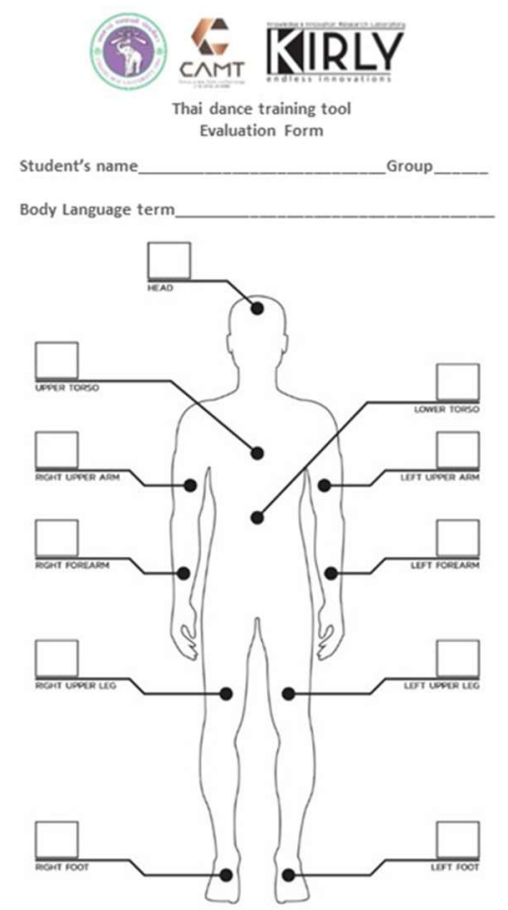

Figure 6: Example of Performance Evaluation Form

The aim of performance assessment is to measure the dance movement according to the learning content. The 
evaluation form is to assess the participant by head, upper Torso (split), upper Torso (hip), right upper arm (shoulder), left upper arm (shoulder), right forearm, left forearm, right hand, left hand, right leg, and left leg. The evaluator or teacher will fill the box's score giving to the participant's body parts performance.

Table 1: Rating for 5-point Likert Scale

\begin{tabular}{|l|l|l|}
\hline \multicolumn{1}{|c|}{ Options } & Points & \multicolumn{1}{c|}{ Rating } \\
\hline Strongly disagree & 1 & $1.00-1.79$ \\
\hline Disagree & 2 & $1.80-2.59$ \\
\hline Neutral & 3 & $2.60-3.39$ \\
\hline Agree & 4 & $3.40-4.19$ \\
\hline Strongly Agree & 5 & $4.20-4.99$ \\
\hline
\end{tabular}

The aim of satisfaction assessment is to measure the interaction and feedback of participants after completed practices with the system. The test consisted of 15 items that ranged from 1 (strongly disagree) to 5 using a 5-point Likert scale (strongly agree). Although it may have been beneficial for survey applicants before they took the test, both before and after this unique selection test, there were organizational restrictions on conducting surveys. The 5-point Likert scale rating is shown in Table 1.

\section{RESULT}

The evaluation session was placed at the end of the class. All participants were asked to demonstrate their Thai dance performance to the Thai dance experts committee. The total scores for the test are 150, which was marked by a three experts committee. The test session took 10 minutes per student.

According to the result, the control group participants achieved over 67 percent in the evaluation session's average score while the experimental group achieved 61.73 percent. The average score of body part section 1 (head, upper torso, and lower torso) in the control group is 68 percent, and the experimental group is 65 percent. Meanwhile, the average score of body part section 2 (right upper arm, left upper arm, right forearm, and left forearm) in the control group is 62 percent, and the experimental group is 60percent. In the last body part section (right upper leg, left upper leg, right foot, and left foot), the control group achieved 65 percent while the experimental group reached 60.5 percent. It can be concluded that the average score of the control groups is better than the experimental groups. This means that the learning pattern of Thai dance conducted by teachers is better than a computer game. Even the learning pattern of computer games might not provide obvious effectives. We observed that it could be improved.

The result of the experiment group who interacted with the computer game, particularly in body part section 1 and 2 , is not different from the control group. If the computer game could provide a good quality of image and interaction in body part 3, it would improve participants' performance, which increases the average score. We believe that the computer game could take place as a learning and practicing tool for Thai dance students in the near future.

The satisfaction form has been given to all participants at the end of the evaluation session. Participants were asked 
to rank the score in three different parts of the satisfaction form. The first part is the Thai dance content, user interface, and future use.

Table 2: The result of the performance evaluation of the Control group \& Experiment group

\begin{tabular}{|c|c|c|c|c|c|c|}
\hline & \multicolumn{3}{|c|}{ Control group } & \multicolumn{3}{|c|}{ Experiment group } \\
\hline Body Parts & Scores & $\%$ & SD & Scores & $\%$ & SD \\
\hline Head & 12 & $40 \%$ & \multirow{2}{*}{0.50} & 10 & $33.3 \%$ & \multirow{2}{*}{0.48} \\
\hline Upper Torso & 18 & $60 \%$ & & 20 & $66.7 \%$ & \\
\hline Lower Torso & 16 & $53.3 \%$ & \multirow{3}{*}{0.76} & 19 & $63.3 \%$ & \multirow{3}{*}{0.68} \\
\hline Right Upper Arm & 9 & $30 \%$ & & 8 & $26.7 \%$ & \\
\hline Left Upper Arm & 5 & $16.7 \%$ & & 3 & $10.0 \%$ & \\
\hline Right Forearm & 9 & $30 \%$ & 0.47 & 7 & $23.3 \%$ & 0.48 \\
\hline Left Forearm & 21 & $70 \%$ & & 22 & $73.4 \%$ & \\
\hline Right Upper Leg & 0 & $0 \%$ & & 1 & $3.3 \%$ & \\
\hline Left Upper Leg & 21 & $70 \%$ & 0.61 & 18 & $60 \%$ & 0.68 \\
\hline Right Foot & 7 & $23.3 \%$ & & 9 & $30 \%$ & \\
\hline Left Foot & 2 & $6.7 \%$ & & 3 & $10 \%$ & $\mathrm{q}$ \\
\hline
\end{tabular}

Overall, the result indicated that all participants' satisfaction level is agreed (3.56 percent) with Thai dance learning and practice patterns. In part 1, the participants were satisfied with the computer game since they were able to interact with fun and enjoyment. The content is similar to the traditional classroom, which was not difficult to understand. However, part 1 showed that the participants were not confident with the correctness of the result since it was automatically calculated with the system.

Table 3: The result of the satisfaction evaluation

\begin{tabular}{|l|l|l|l|l|}
\hline \multirow{2}{*}{} & \multicolumn{2}{|l|}{ Control group } & \multicolumn{2}{l|}{ Experimental group } \\
\cline { 2 - 5 } & Respond & Mean & Respond & Mean \\
\hline I1 & Strongly Agree & 4.19 & Agree & 3.51 \\
\hline I2 & Strongly Agree & 4.26 & Agree & 3.45 \\
\hline I3 & Strongly Agree & 4.42 & Agree & 3.66 \\
\hline I4 & Neutral & 2.80 & Neutral & 3.57 \\
\hline I5 & Strongly Agree & 4.17 & Agree & 3.89 \\
\hline
\end{tabular}




\begin{tabular}{|l|l|l|l|l|}
\hline $\mathbf{I 6}$ & Disagree & 1.29 & Neutral & 3.24 \\
\hline $\mathbf{I 7}$ & Agree & 3.44 & Disagree & 3.74 \\
\hline $\mathbf{I 8}$ & Agree & 3.51 & Agree & 3.95 \\
\hline $\mathbf{I 9}$ & Strongly Agree & 4.18 & Neutral & 3.31 \\
\hline $\mathbf{I 1 0}$ & Neutral & 2.70 & Neutral & 2.88 \\
\hline $\mathbf{I 1 1}$ & Strongly Agree & 4.09 & Disagree & 2.23 \\
\hline $\mathbf{I 1 2}$ & Agree & 3.61 & Disagree & 2.31 \\
\hline $\mathbf{I 1 3}$ & Neutral & 2.87 & Agree & 2.65 \\
\hline $\mathbf{I 1 4}$ & Strongly Agree & 4.09 & $\begin{array}{l}\text { Strongly } \\
\text { Agree }\end{array}$ & 4.12 \\
\hline I15 & Agree & 3.43 & Agree & 3.71 \\
\hline
\end{tabular}

Furthermore, the participants wished to have more learning content that they were able to practice more. In part 2, the result indicated that the participants were satisfied with the computer game's user interaction. The game logic is easy to understand while the interaction feature is clearly visible. The game element (leaderboard) in the system is the most attractive feature that motivates users to interact. However, we also found that the participants suffered from the feature that searches the game's learning content. Therefore, we propose that the search feature in the game should re-design. The result in the final part indicates that the participant tended to use computer games for their learning and practicing Thai dance. The game allowed participants to interact with Thai dance content freely with their friends. Without the teacher and other experts, students able to express their performance with their own style. The game provided a competitive environment for them.

\section{DISCUSSIONS}

For the performance evaluation, the Thai dance training tool serves the purpose of transferring Thai dance knowledge and could transfer Thai dance knowledge as same as the teacher. However, in some particular part of the movement, the system could not deliver as same as the Thai dance teacher. For example, the movement of the wrist and the ankle, the system could not demonstrate both parts of the body good enough. Therefore, the demonstration part could display the real human expert's movement instead of 3D human figure animation. For the satisfaction evaluation, it is acceptable that overall Thai dance students satisfy the Thai dance training tool, and they would like to learn more from the system and request more dance gestures and songs.

\section{CONCLUSIONS}

In conclusion, by comparing motion capture data to real-time motion data, the Thai dance training tool could transfer Thai dance knowledge from Thai expert knowledge to Thai dance learners. Two evaluation process had experimented on twenty Thai dance students. They were separated into two groups, the control group and the experimental group. According to the result of the performance evaluation, the participants in the control group completed over 67 percent in the average score of 
the evaluation session while the experimental group completed 61.73 percent. It can be indicated that the average score of the control groups is better than the experimental groups. This means that the Thai dance learning process, which is conducted by the Thai dance teachers, is better than the Thai dance training tool. The system might not provide a clear, effective demonstration; however, the system could be improved in the next version.

For the satisfaction evaluation, the first part is Thai dance content, user interface, and future use. Generally, the result indicated that all participants' satisfaction level is agreed (3.56 percent) with the Thai dance movement's learning and practice patterns. The participants were satisfied with the system since they were able to interact with fun and enjoyment. The second part is the user interaction. From the result indicated that the participants were satisfied with the system's user interaction. The game logic is easy to understand while the interaction feature is clearly visible. The leaderboard is the most attractive feature in which motivates the user to come back for more practice. However, some participants suffered from the menu feature's misdirection to reach the system's learning content. This mistake can be improved by re-design the flow of the menu. In the last part of the satisfaction evaluation result, the participant tended to use the system to learn and practice the Thai dance gesture. The system allowed participants to interact with Thai dance content freely with their friends without their teacher. The students will be able to practice and express their performance in their own style.

Therefore, the Thai dance training tool provided a good learning environment for the Thai dance students, which enhanced their performance. And the system will become the innovation platform for improving the performance of Thai dance students with more accuracy in the future.

\section{ACKNOWLEDGMENT}

This study would never be successful without the kind support of the Knowledge and Innovation Research Laboratory (KIRLY), College of Arts, Media and Technology, Chiang Mai University, Thailand. In addition, special thanks to Research and Innovation Staff Exchange (RISE) called H2020-MSCA-RISE-2015 in the project called "High Dimensional Heterogeneous Data based Animation Techniques for Southeast Asian Intangible Cultural Heritage Digital Content" or "AniAge Project" for supporting us with mobility funds [EU H2020 project-AniAge (691215)]. Last, this study would never be successful without the kind support of Université d'Artois/CNRS, CRIL, France.

\section{REFERENCES}

1. AniAge Project, "ANIAGE - EU H2020-MSCA-RISE-691215" Retrieved May 8, 2017, https://www.euh2020aniage.org/

2. Ann. G. Hutchinson. "Choreographic: A Comparison of Dance Notation Systems from the Fifteenth Century to the Present" Retrieved January 15, 2017. Kindle Edition, 1st published 1989, Gordon and Breach Publishers, Published 2014 by Routledge.

3. Cheung, K. K. F., Jong, M.S. Y., Lee, F. L., Lee, J. H. M., Luk, E. T. H., Shang, J., \& Wong, M. K. H., "FARMTASIA: an online game-based learning environment based on the VISOLE pedagogy", 2008, Virtual Reality, 12(1), 17-25

4. Chang Y., Hwang J., Fang R., Lu Y., "A Kinect- and Game-Based Interactive Learning System", EURASIA Journal of Mathematics Science and Technology Education ISSN: 1305-8223 (online) 1305-8215 (print) 2017 13(8):4897-4914.

5. Chommanad K. "Labanotation: From Researching on Dance Vocabularies to the Studies of the Essence of Thai Classical Dance". The 26th International Biennial Conference of ICKL, 2009. Retrieved January 8, 2016.

6. Garris, R., Ahlers, R., \& Driskell, J. E., "Games, Motivation, and Learning: A Research and Practice Model", 2002, Games, motivation and learning, simulation \& gaming: An Interdisciplinary Journal Practice and Research. Simulation Gaming 
December, 33(4), 441-467.

7. Ghergulescu, I., \& Muntean, C. H., "Motivation monitoring and assessment extension for Input-Process-Outcome game model", 2014, International Journal of Game-Based Learning (IJGBL), 4(2), 15-35.

8. Helie S., Sun R., "Incubation, Insight, and Creative Problem Solving: A Unified Theory and a Connectionist Model", 2010, (PDF). Psychological Review. 117 (3): 994-1024. doi:10.1037/a0019532. PMID 20658861.

9. Hugh. H, "When Will a Motion-Capture Actor Win an Oscar?", 2012 Retrieved May 26, 2015, https://www.wired.com/2012/01/andy-serkis-oscars/

10. ICOMOS, International Cultural Tourism Charter. Principles and Guidelines for Managing Tourism at Places of Cultural and Heritage Significance. ICOMOS International Cultural Tourism Committee. 2002.

11. Jukka O. Miettinen, "Asian Traditional Theater and Dance", 2010, Retrieved Jun 20, 2016 https://disco.teak.fi/asia/lakhonforms-of-dance-dramal

12. Nonaka I, Hirotaka T, "The Knowledge-Creating Company: How Japanese Comapnies Create the Dynamics of Innovation", Ikujior Nonaka and Hirotaka Takeuchi, Oxford University Press (1995)

13. Ob-orm M, Pradorn S, Karim T, "Dance Training Tool Using Kinect-Based Skeleton Tracking and Evaluating Dancer's Performance", International Conference on Industrial, Engineering and Other Applications of Applied Intelligent Systems 2017 , DOI: 10.1007/978-3-319-60045-1_4

14. Prensky, M., "Digital Game-Based Learning", 2001, McGraw-Hill, New York.

15. Strategic Development Plan, "Objective plan", 2019, Retrieved Jun 20, 2019 http://www.bpi.ac.th/index.php/en/aboutus/management/management6

16. Sirada P, "THAI DRAMATIC DANCE CREATION ART AND CRAFTS IN PHATHUM THANI", The 9th International Festival of Arts and Culture 2019, Srinakharinwirot University, Bangkok, Page 103-108, Thailand, retrieved on January 18th, 2020, http://fofa.swu.ac.th/wp-content/uploads/2019/11/the-creative-work-the-9th-international-festival-of-arts-and-culture-201916-10-62.pdf

17. Suepphong C, Pradorn S, Karim T, Yoeven D K, "Thai dance training game-based model", International Conference on Digital Arts, Media and Technology 2018 (ICDAMT 2018), DOI: 10.1109/ICDAMT.2018.8376522

18. Treasures of The Kingdom, “เอกสารประกอบ ตำรารำ," สำนักงานอุทยานการเรียนรู้ สังกัดสำนักงานบริหารและพัฒนาองค์ความรู้ $\quad$ (องค์การมหาชน), $2012, \quad$ Retrieved $\quad \operatorname{Jan} \quad 25, \quad 2015$, http://valuablebook2.tkpark.or.th/2013/08_tumra_web/document.html

19. Tsai C H, Yen J C, "Effect of an Equivalent Fractions Digital Game on the Learning Outcome, Motivation, and Flow Types Among Elementary School Students", 2016, International Conference on Educational Innovation through Technology, 70-75.

20. UNESCO "Intangible Cultural Heritage domains" 2003, Retrieved May 26, 2016, https://ich.unesco.org/doc/src/01857-EN.pdf

21. UNESCO "World Heritage Earthen Architecture Programme (WHEAP)." 2007, Retrieved May 26, 2015 , https://whc.unesco.org/en/earthen-architecture/

22. Yootthapong T, Patcharaphon S, Pradorn S, "Evaluating Real-Time Thai Dance Using Thai Dance Training Tool" International Conference on Digital Arts, Media and Technology 2018 (ICDAMT 2018), page 185-189, IEEE, 2018 
23. Yootthapong T, Pradorn S, Mongkhol R, Hongchuan Y, "Thai dance knowledge archive framework based on Labanotation represented in 3D animation". International Conference on Digital Arts, Media and Technology 2017 (ICDAMT 2017), page 66-70, IEEE, 2017 